\title{
Avaliação da presença de microrganismos indicadores higiênico-sanitários em alimentos servidos em escolas públicas de Porto Alegre, Brasil
}

\author{
Evaluation of the presence of hygienic \\ and sanitary indicator microorganisms in food served \\ in public schools in Porto Alegre, Brazil
}

\author{
Ana Beatriz Almeida de Oliveira ${ }^{1}$ \\ Roberta Capalonga ${ }^{2}$ \\ Joice Trindade Silveira ${ }^{3}$ \\ Eduardo Cesar Tondo ${ }^{4}$ \\ Marisa Ribeiro de Itapema Cardoso ${ }^{5}$
}

\footnotetext{
${ }^{1}$ Departamento de Medicina Social, Universidade Federal do Rio Grande do Sul. Rua Ramiro Barcelos 2400/4\%, Bairro Santana. 900035-003 Porto Alegre RS. ana.beatriz@ufros.br ${ }^{2}$ CECANE, Universidade Federal do Rio Grande do Sul.

${ }^{3}$ Universidade Federal do Pampa (UNIPAMPA).

${ }^{4}$ Departamento Ciência dos Alimentos, Instituto de Ciências e Tecnologia dos Alimentos, Universidade Federal do Rio Grande do Sul.

${ }^{5}$ Departamento de Medicina Veterinária Preventiva, Faculdade de Veterinária, Universidade Federal do Rio Grande do Sul
}

\begin{abstract}
The objective of this study was to evaluate the presence of hygienic and sanitary indicator microorganisms in samples of food served in public schools in Porto Alegre. All the food served in the meal of the session visited was analyzed for Escherichia coli, coagulase-positive Staphylococcus, Salmonella sp. and Shigella sp. Of the total of 196 food products analyzed in 120 schools, 4 contained and Escherichia coli score above the permitted level, and 2 contained coagulase-positive Staphylococcus. Neither Shigella nor Salmonella genus were detected. In the majority of schools studied, it was found that food was of an adequate hygienic-sanitary standard. However, only municipal schools had the supervision of a technician responsible for school food. In the state schools, 60\% had never been visited by a nutritionist and in these schools several procedures failed to comply with legal requirements. In most of the schools studied, the food served to students was within adequate standards, though the problems detected revealed the need for the implementation of Best Practices in the school environment.
\end{abstract} Key words Food security, Schools, E. coli, Coagulase-positive Staphylococcus, Food handling
Resumo Este estudo tem por objetivo avaliar a presença de microrganismos indicadores higiênico-sanitários em amostras de alimentos servidos em escolas públicas de Porto Alegre. Foram analisados todos os alimentos servidos na refeição do turno da visita, quanto à presença de Escherichia coli, Staphylococcus coagulase positiva, Salmonella sp. e Shigella sp. No total de 196 alimentos analisados de 120 escolas, 4 apresentavam contagem de Escherichia coli acima do permitido e dois tinham a presença de Staphylococcus coagulase positiva. Os gêneros Shigella e Salmonella não foram encontrados. Foi observado que a maioria das escolas estudadas servia alimentos dentro de padrões higiênico-sanitários adequados. Foi evidenciado que somente escolas municipais contavam com a orientação de responsável técnico pela alimentação escolar. Das escolas estaduais 60\% nunca haviam recebido visita de nutricionista nas quais foram encontrados procedimentos em desacordo com as exigências da legislação. Na maioria das escolas, os alimentos servidos estavam dentro de padrões adequados, porém os problemas detectados demonstram a necessidade da implantação das Boas Práticas no ambiente escolar.

Palavras-chave Segurança dos alimentos, Escolas, E. coli, Staphylococcus coagulase positiva, Manipulação de alimentos 


\section{Introdução}

De acordo com os princípios de uma alimentação saudável, todos os grupos de alimentos devem compor a dieta diária, a qual deve fornecer água, carboidratos, proteínas, lipídios, vitaminas, fibras e minerais, que são insubstituíveis e indispensáveis ao bom funcionamento do organismo ${ }^{1,2}$.

Os alimentos oferecidos aos escolares devem satisfazer parte de suas exigências biológicas, sendo essencial que possam ser aproveitados pelo organismo e tenham condição de exercer sua função nutricional ${ }^{3}$. Além disso, os alimentos devem ser inócuos, uma vez que as Doenças Transmitidas por Alimentos (DTA) são uma das principais causas que contribuem para os índices de morbidade no país ${ }^{3,4}$.

O Programa Nacional de Alimentação Escolar (PNAE), criado em 1955, e atualmente gerenciado pelo Fundo Nacional de Desenvolvimento da Educação (FNDE) do Ministério da Educação, atendeu 45 milhões de escolares no ano de 2010 , o que representa mais de $25 \%$ da população brasileira, visando fornecer uma alimentação saudável e contribuir para o desenvolvimento e o aprendizado dos alunos. O programa é organizado de forma que o governo federal transfere recursos financeiros para a aquisição de gêneros alimentícios destinados a suprir parte das necessidades nutricionais dos estudantes, enquanto que estados e municípios são responsáveis pela complementação desses recursos e distribuição dos alimentos nas escolas de ensino público do país ${ }^{3-5}$.

Com o objetivo de qualificar a gestão e o controle social do PNAE, foram instituídos oito Centros Colaboradores em Alimentação e Nutrição do Escolar (CECANE), em uma parceria entre o FNDE e universidades federais brasileiras ${ }^{6}$. O CECANE da Universidade Federal do Rio Grande do Sul (UFRGS) tem atuado regionalmente, realizando pesquisas e ações de apoio técnico aos municípios do estado. As atividades desenvolvidas pelo CECANE UFRGS abrangem a capacitação de profissionais que atuam na preparação da alimentação nas escolas, a avaliação da situação nutricional dos estudantes, bem como o levantamento da qualidade dos alimentos servidos nas escolas.

Nesse contexto, o objetivo deste estudo foi verificar a qualidade higiênico-sanitária dos alimentos servidos em escolas públicas do município de Porto Alegre.

\section{Métodos}

\section{Delineamento experimental}

Um estudo transversal foi conduzido em escolas públicas municipais e estaduais, atendidas pelo PNAE, localizadas no município de Porto Alegre e que contavam com mais de 100 alunos matriculados no período de outubro de 2008 a junho de 2009.

Do total de 282 escolas públicas, 120 foram selecionadas para fazerem parte da amostra a ser estudada. Para o cálculo desta amostra utilizou-se intervalo de confiança de $95 \%$ e o software EPI-INFO, versão 3.5.1.

Com o intuito de manter a proporção dos dois estratos de escolas (estaduais e municipais) no total de amostras, determinou-se que seriam coletadas amostras em 100 escolas estaduais e 20 municipais. As unidades amostradas foram sorteadas a partir dos cadastros de escolas públicas de cada um dos estratos, disponíveis na Secretaria Estadual de Educação e Secretaria Municipal de Educação.

Todas as escolas foram visitadas, sem aviso prévio, após autorização das respectivas Secretarias de Educação. Foi requerido o consentimento livre e esclarecido de todos os entrevistados. Em cada escola foram analisados todos os alimentos servidos na refeição do turno da visita. Devido à diversidade de tipos de alimentos entre escolas, as amostras foram avaliadas quanto à contagem de dois indicadores higiênico-sanitários (Escherichia coli e Staphylococcus coagulase positiva) e presença de Salmonella spp. e Shigella spp.

Esse estudo foi submetido e aprovado pela Comissão de Ética em Pesquisa da Universidade Federal do Rio Grande do Sul.

\section{Coleta de dados}

Em cada escola amostrada, foi aplicado um questionário aos manipuladores de alimentos com perguntas sobre: $i$. presença de responsável técnico (nutricionista); ii. existência de Manual de Boas Práticas (MBP); iii. treinamento dos manipuladores; $i v$. utilização de equipamento térmico para manter a temperatura dos alimentos no momento da distribuição; $v$. higienização das verduras, legumes e frutas distribuídos aos escolares com solução clorada (200 a 250 ppm) por 15 minutos, seguida de enxágue em água potável, conforme legislação vigente ${ }^{7}$. 


\section{Coleta das amostras}

Foram coletados $100 \mathrm{~g}$ de cada alimento, os quais foram acondicionados, individualmente, em sacos plásticos estéreis, que foram fechados, identificados e armazenados em bolsas térmicas para transporte até o Laboratório de Medicina Veterinária Preventiva da UFRGS.

Alíquotas (25 g ou $25 \mathrm{~mL}$ ) de cada amostra de alimento foram retiradas assepticamente e diluídas $\left(10^{-1}\right)$ em $225 \mathrm{~mL}$ de Água Peptonada (AP) $0,1 \%$, homogeneizadas em vórtice (Interscience) por 5 segundos e, a seguir, diluídas até $10^{-}$ ${ }^{2}$ e $10^{-3}$ em AP $0,1 \%$.

\section{Enumeração}

de Staphylococcus coagulase positiva

Alíquotas $(0,1 \mathrm{~mL})$ das diluições realizadas em AP 0,1\% foram semeadas em ágar Baird-Parker (BP - Merck, Darmstadt, Germany) suplementado com emulsão de gema de ovo e telurito ( $E g g$ Yolk Tellurite Emulsion - Merck). As placas foram incubadas a $36 \pm 1^{\circ} \mathrm{C}$ por 24 a 48 horas, e as colônias típicas do gênero Staphylococcus (negras brilhantes com anel opaco, rodeadas por um halo claro, transparente e destacado sobre a opacidade do meio) foram contadas. Cinco colônias típicas foram transferidas, individualmente, para caldo Infusão Cérebro e Coração (BHI - Merck), Incubadas por $18 \mathrm{~h}$ a $37^{\circ} \mathrm{C}$. Após, alíquotas $(0,2$ $\mathrm{mL}$ ) da cultura foram adicionadas a $0,5 \mathrm{~mL}$ de plasma de coelho (Laborclin), homogeneizadas e incubadas a $37 \pm 1^{\circ} \mathrm{C}$. Em intervalos de uma hora, por até quatro horas, os tubos foram avaliados quanto à presença de coágulo. Nos tubos em que a reação não foi observada nesse período, estendeu-se a incubação por até 24 horas. Colônias que resultaram em formação de coágulo foram confirmadas como coagulase positivas. O cálculo do número de Unidades Formadoras de Colônia de Stapylococcus coagulase positiva foi calculado de acordo com Silva et al. ${ }^{8}$, pela seguinte fórmula:

UFC/g ou $\mathrm{mL}$ de alimento = Número de colônias típicas x Inverso da Diluição x 10 x \% colônias confirmadas.

\section{Enumeração de Escherichia coli}

Para a contagem de E.coli foi adaptado o método de Silva et al. ${ }^{8}$, em que foi pipetado, em duplicata, $1 \mathrm{~mL}$ de cada diluição em AP 0,1\% em placas de Petri estéreis. A seguir, foi vertido cerca de $10 \mathrm{~mL}$ de Ágar Vermelho Violeta Bile com Lactose (VRB - Merck), previamente fundido. Após homogeneização e repouso até solidificação, foi vertido cerca de $5 \mathrm{~mL}$ para formação de sobre camada. Após solidificação do meio, as placas foram incubadas a $36 \pm 1^{\circ} \mathrm{C}$ por 24 horas. Após, colônias características de enterobactérias (vermelho púrpura, rodeados por halo avermelhado de precipitação de sais biliares) foram contadas. Cinco colônias características foram inoculadas em tubos contendo caldo MUG Lauril Sulfato (Himedia, Índia), providos de tubos Durhan, e mantidos em banho-maria $\left(36 \pm 1^{\circ} \mathrm{C}\right.$ por 24 horas). A confirmação de E. coli foi feita pela presença de fluorescência, quando da exposição do tubo à luz ultravioleta $(365 \mathrm{~nm})$. A enumeração de $E$. coli foi feita pela seguinte fórmula:

UFC/g ou $\mathrm{mL}$ de alimento = Número de colônias típicas x Inverso da Diluição x \% colônias confirmadas.

Pesquisa de Salmonella sp. e Shigella sp.

Para isolamento e identificação de Salmonella sp. e Shigella sp., as amostras (25 g ou $25 \mathrm{~mL}$ ) foram acrescidas à Água Peptonada Tamponada $1 \%$ (APT, Merck), homogeneizadas e incubadas a $36 \pm 1^{\circ} \mathrm{C}$ por $24 \mathrm{~h}$. Alíquotas de $1 \mathrm{~mL}$ foram repicadas para caldo Tetrationato (Merck) e 0,1 $\mathrm{mL}$ para caldo Rappaport - Vassiliadis (Merck), sendo mantidas em banho-maria a $42^{\circ} \mathrm{C}$ por $24 \mathrm{~h}$. A partir dos caldos seletivos, foram repicados, em placas de ágar SS (Salmonella e Shigella Merck) e ágar XLD (Xilose-Lisina Desoxicolato - Merck). Estas placas foram incubadas a $36 \pm$ $1^{\circ} \mathrm{C}$ por 24 horas. Posteriormente foram observadas e as colônias típicas ou suspeitas foram repicadas em ágar Triptona de Soja (TSA - Merck) e confirmadas por testes bioquímicos conforme Silva et al. ${ }^{8}$.

\section{Análise dos resultados}

Os alimentos servidos nas escolas foram classificados de acordo com a classificação hierárquica de risco de veiculação de agentes causadores de surtos de DTA, segundo Greig e Ravel' ${ }^{9}$. Os tipos de alimentos servidos nas escolas municipais e estaduais foram comparados pelo Teste Qui-quadrado ou Teste Exato de Fisher, em nível de significância de P $<0,05$. As contagens de $E$. coli obtidas foram comparadas com os parâmetros estabelecidos para Coliformes a $45^{\circ} \mathrm{C}$ na RDC 12/2001 ${ }^{10}$.

\section{Resultados}

Das 120 escolas estudadas, foram analisados 196 alimentos, sendo 149 (76\%) coletados em escolas estaduais e 47 (24\%) em escolas municipais. O número de alimentos coletados por escola va- 
riou de acordo com as preparações servidas por cada no dia da coleta (variando de um a cinco).

Os alimentos coletados foram distribuídos de forma heterogênea nos grupos hierárquicos de maior ou menor risco de veiculação de agentes causadores de DTA, conforme Greig e Ravel ${ }^{9}$ (Tabela 1). O maior número de amostras coletadas foi classificado no grupo dos cereais e leguminosas, seguida do grupo de cereais e carnes, tanto em escolas municipais como nas estaduais (Figura 1). Estes dois grupos representaram 46\% dos alimentos coletados. Entretanto, nas escolas estaduais, o terceiro grupo mais frequente foi o de biscoitos, bolachas e bolos (17\%), enquanto nas municipais foi de carne bovina e de frango $(15 \%)$. As escolas municipais serviram significativamente mais carne, frango e ovos $(\mathrm{P}<0,05)$ e cereais $(\mathrm{P}<0,04)$ do que as escolas estaduais.

$\mathrm{Na}$ amostra de leite com banana, em que foi isolado Staphylococcus coagulase positiva, também foi constatada a presença de E. coli. Essa foi a única preparação no qual foram isolados dois tipos de bactérias potencialmente patogênicas.

Os cinco alimentos com presença de E. coli em contagem acima da permitida pela legislação vigente para Coliformes a $45^{\circ} \mathrm{C}$ foram os seguintes: dois leites achocolatados; um leite achocolatado adicionado de aveia e duas amostras de bo-

Tabela 1. Alimentos coletados em 120 escolas da rede pública de ensino de Porto Alegre/RS, distribuídos de acordo com a classificação crescente de risco de envolvimento em surtos de Doenças Transmitidas por Alimentos, proposta por Greig e Ravel (2009) $)^{9}$ - Porto Alegre, 2011.

\section{Categorias Subcategorias}

( $\mathrm{N}^{\circ}$ de preparações coletadas $) \quad\left(\mathrm{N}^{\circ}\right.$ de preparações coletadas $)$

1 Carne Bovina (7)

2 Carne de frango (4)

3 Embutidos (3)

Ovos (1)

Produtos Lácteos (24)

6 Multi-ingredientes Produtos lácteos(12)

$7 \quad$ Frutas e Verduras (14)

8 Cereais e leguminosas (51)

9 Multi-ingredientes cereais e carnes (40)

10 Bebidas (6)

11 Bolos, bolachas, biscoitos e pães (29)

12 Doces sem leite (5) Total
Carne com molho (3) Carne moída (2)

Hambúrger (1) Almôndega (1)

Frango com molho (4)

Salsicha (1) Patê (2)

Leite com gemada (1)

Leite com achocolatado (10) Creme (11)

Leite (2) Iogurte (1)

Leite com cereal (4) Arroz doce (2)

Torta de bolacha (2)Vitamina (2)

Creme de banana caramelada (1) Milho com leite (1)

Salada de frutas (2) Salada de repolho (2)

Salada de alface (2) Salada de beterraba (1)

Salada de repolho e tomate (2)

Salada de cenoura e repolho (1)

Salada de vagem (1)

Salada de repolho, tomate e rúcula (1)

Salada de tomate e cebola (1)

Salada de couve, cenoura, repolho e grão de bico (1)

Arroz (14) Feijão (14) Lentilha (8)

Polenta (9) Aipim (1) Macarrão (1)

Batata doce (1) Cereal de milho (3)

Macarrão com molho de carnes (8) Carreteiro (6)

Risoto (5) Molho com salsicha (4) Molho (2)

Sopa (3) Cachorro quente (2)

Arroz com salsicha (2) Macarrão com molho (1)

Guisado com batata (1) Aipim com carne (1)

Frango com seleta de legumes (1)

Presunto, queijo e maionese (1)

Torta de legumes (1) Pizza de salsicha (1)

Arroz com milho e ervilha (1)

Suco de fruta em pó (5) Chá-mate (1)

Bolacha doce (14) Pão (8) Bolacha salgada (3)

Bolo (2) Bolo frito (1) Cuca (1)

Sagu (4) Gelatina (1)

196 


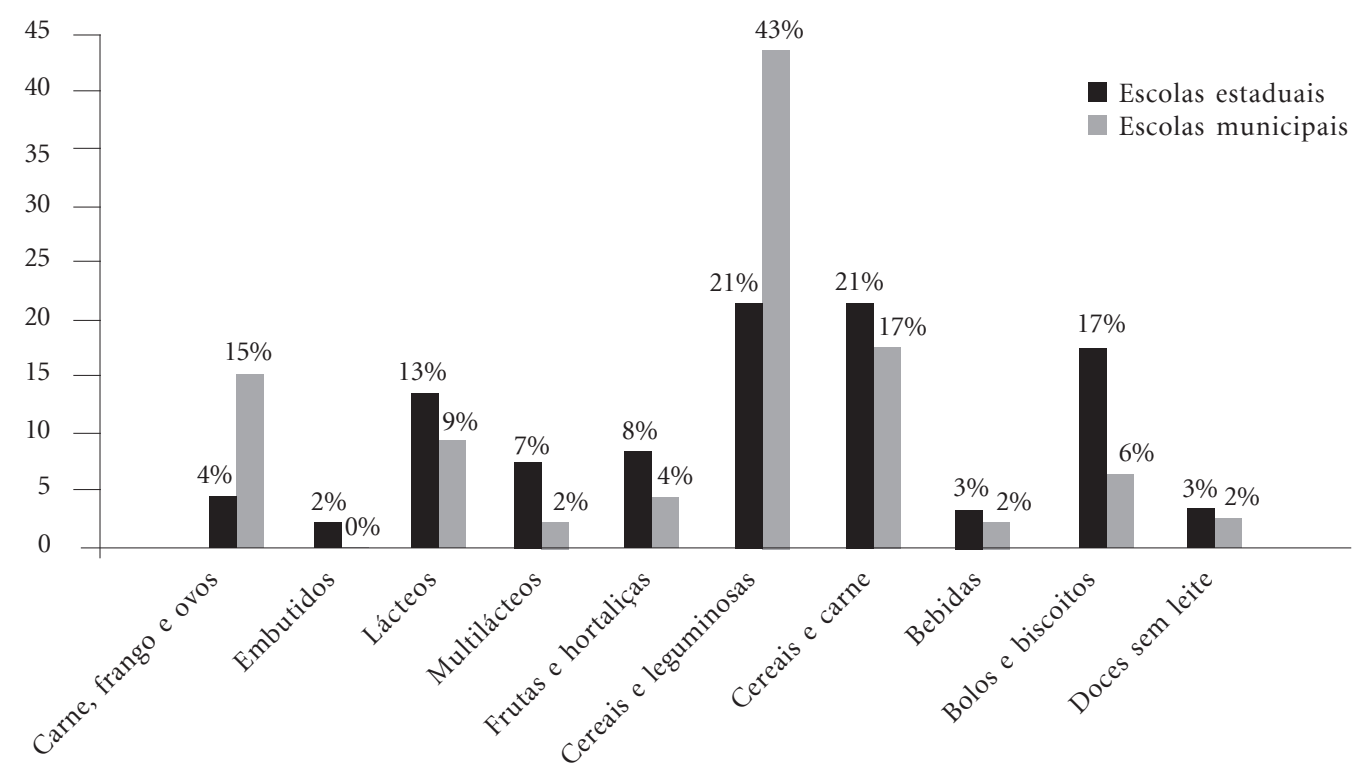

Figura 1. Distribuição dos grupos de alimentos servidos em escolas estaduais e municipais de Porto Alegre Porto Alegre, 2011.

lacha doce. Desses, dois alimentos (um leite achocolatado e uma amostra de bolacha doce) foram coletados na mesma escola. Em outras duas escolas (uma estadual e uma municipal), também foram encontrados mais de um alimento com presença de E. coli. Nesse caso, porém, as contagens desta bactéria estavam abaixo do limite previsto para Coliformes a $45^{\circ} \mathrm{C}^{10}$ (Tabela 2).

A partir do questionário aplicado nas 120 escolas, foi verificado que $83 \%$ não desinfetavam, na forma indicada pela legislação ${ }^{7,11}$, as verduras, os legumes e as frutas que seriam ingeridos crus ou com casca. Todas as escolas municipais possuíam equipamento térmico para manter os alimentos quentes durante a distribuição das refeições, enquanto nas escolas estaduais, apenas em oito (8\%) havia esse equipamento.

Ficou demonstrado que as escolas municipais mantinham um responsável técnico (nutricionista) para cada dez escolas; enquanto mais de $60 \%$ das escolas estaduais nunca havia recebido assessoramento técnico. Quanto à presença de MBP, $78 \%$ das escolas estaduais e $30 \%$ das municipais não o possuíam. Os manipuladores de alimentos, em 69\% das escolas, já tinham recebido algum tipo de capacitação sobre segurança dos alimentos.

\section{Discussão}

Entre os 196 alimentos amostrados, cinco tinham a presença de E.coli acima dos parâmetros da legislação para Coliformes à $45^{\circ} \mathrm{C}$, e em dois foi encontrado Staphylococcus coagulase positiva. Essas bactérias são utilizadas como indicadores higiênico-sanitários da manipulação de alimentos. E. coli pertence ao grupo dos coliformes a $45^{\circ} \mathrm{C}$, porém, ao contrário destes, tem origem exclusivamente fecal. Dessa forma, é considerado o indicador de contaminação fecal mais específico $^{11,12}$. Por outro lado, Staphylococcus coagulase positiva podem estar presentes na pele e mucosas dos humanos, e indicam falhas na manipulação dos alimentos ${ }^{13,14}$.

Os sete alimentos considerados fora dos padrões higiênico-sanitários adequados eram todos provenientes de escolas estaduais, apesar das escolas municipais servirem alimentos de grupo de maior risco (carne, frango e ovos) com maior frequência.

O leite, alimento que participou de três amostras do total acima citado, ocupa um lugar de destaque do ponto de vista nutricional, por ser um dos alimentos mais ricos em nutrientes, prin- 


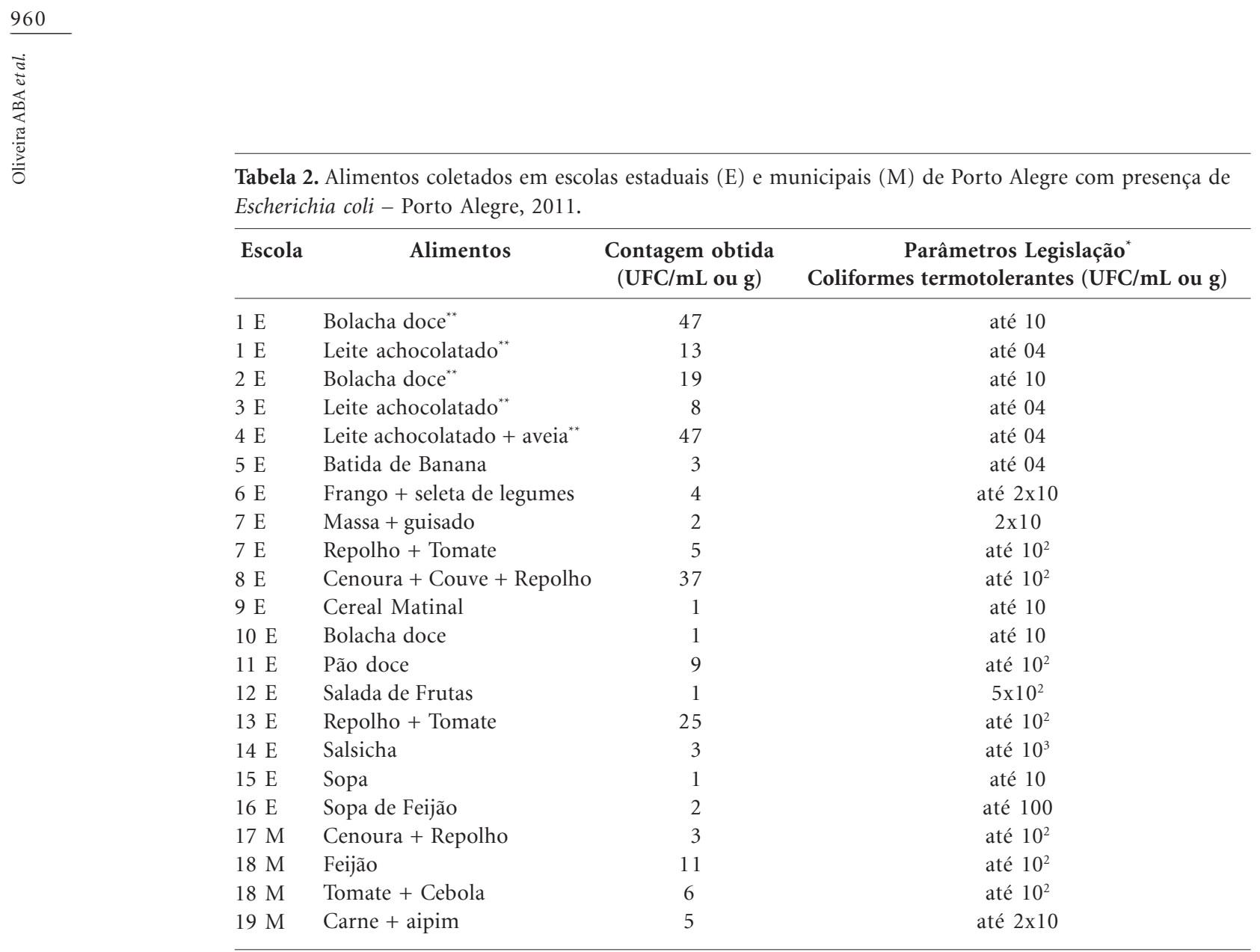

${ }^{*}$ RDC 12/2001; ** Alimentos com contagem de E.coli acima do previsto na legislação para Coliformes a $45^{\circ} \mathrm{C}$

cipalmente cálcio. O qual é particularmente importante para os escolares em fase de crescimento ${ }^{2}$. Por outro lado, é um alimento classificado como de alto risco como fonte veiculadora de patógenos 9 . Segundo Buyser et al. ${ }^{15}$, esse tipo de alimento pode estar envolvido em 2-6\% dos surtos de DTA de origem bacteriana.

Ao contrário, as bolachas doces apresentam baixa atividade de água, o que não favorece a multiplicação bacteriana, sendo, portanto, considerados alimentos de baixo risco. Além disso, é um alimento não recomendável como principal fonte de alimentação, devido à elevada quantidade de calorias em relação à baixa quantidade de nutrientes ${ }^{2}$. Nas duas amostras de bolacha doce com presença de E. coli possivelmente tenha ocorrido contaminação cruzada, pois o contato direto das mãos ou recipientes contaminados pode ser suficiente para transferir para o produto uma quantidade de bactérias suficiente até mesmo para causar doença ${ }^{16}$. A contaminação cruzada durante o preparo dos alimentos também pôde ser evidenciado em três escolas que apresentaram mais de um alimento de diferentes grupos hierárquicos com presença de E.coli.
A presença de Staphylococcus coagulase positiva numa amostra de leite com banana e no pão com margarina, também indica falhas de processamento, pois o preparo desse alimento envolve a manipulação ou o contato com equipamentos de risco, como o liquidificador. Além disso, essas preparações são ingeridas sem tratamento térmico prévio e este microrganismo tem sido frequentemente responsável por surtos de toxinose alimentar ${ }^{13,14}$.

Os demais alimentos coletados apresentavam ausência ou baixas contagens de E.coli. Dentre estes, encontravam-se os alimentos do grupo de cereais/leguminosas e cereais/carnes que constituíram 46\% dos alimentos servidos nas escolas. No grupo dos cereais/leguminosas a preparação, tipicamente brasileira, arroz com feijão foi a mais frequente, sendo uma combinação alimentar saudável, pois os aminoácidos, lisina (feijão) e metionina (arroz) são complementares nutricionalmente $^{17,18}$.

A presença das carnes no cardápio dos escolares também é considerada imprescindível, pois contém nutrientes fundamentais para o crescimento e desempenham a função construtora no 
organismo humano. São fontes de proteínas de alto valor biológico, gorduras, vitaminas, principalmente as do complexo B, e minerais, como o ferro $^{2,19}$. Observa-se que o grupo das carnes estava significativamente mais presente nas escolas municipais do que nas estaduais. Este grupo de alimentos não apresentou presença de E. coli ou Staphylococcus coagulase positiva, sugerindo que as escolas realizavam cozimento suficiente e mantinham a temperatura adequada no momento da distribuição do alimento aos escolares não permitindo a proliferação de microrganismos. Apesar de constituírem o grupo de maior risco para ocorrência de DTA, a presença de E. coli, em baixas contagens, só foi detectada quando a carne estava combinada com outros ingredientes (frango com seleta de legumes, massa com guisado, carne com aipim), provavelmente devido ao maior contato com manipuladores e superfícies contaminadas, exigido durante sua preparação ${ }^{20}$.

Segundo Greig et al. ${ }^{16}$, todas as DTA são fundamentalmente evitáveis por meio da modificação da conduta dos manipuladores. Os resultados do presente estudo demonstraram que a maioria dos manipuladores das escolas já tinha recebido algum tipo de formação sobre a inocuidade dos alimentos, porém avaliações periódicas de sua conduta são necessárias ${ }^{21}$. A supervisão e o controle da rotina dos serviços de alimentação também devem ser efetuados para garantir que os procedimentos sejam implantados de forma eficaz. Um estudo para verificar os conhecimentos de manipuladores em escolas públicas municipais de Botucatu, constatou um "elevado grau de incapacitação" desses manipuladores para o desenvolvimento de suas funções, sinalizando a necessidade de treinamento acompanhado de uma supervisão periódica ${ }^{22}$. Os responsáveis pela produção de refeições devem ter conhecimento dos princípios e práticas de higiene dos alimentos, a fim de avaliar os riscos potenciais e tomar medidas necessárias para corrigir as deficiências ${ }^{7,21}$.

Em muitas escolas estaduais, a responsabilidade da coordenação da alimentação escolar cabia à direção da escola, que não possuía formação técnica para exercer este tipo de supervisão. No Brasil, a Resolução do Conselho Federal de Nutricionistas - CFN no 465/2010 dispõe sobre as atribuições do nutricionista no PNAE, dentre elas: a elaboração e o acompanhamento dos cardápios, a elaboração do MBP e o acompanhamento dos envolvidos na alimentação escolar para que os alimentos servidos alcancem os ob- jetivos de satisfazer as necessidades nutricionais e manter a saúde dos escolares. A falta desse profissional, na maioria das escolas estaduais, teve como consequência a ausência do MBP, o que está em desacordo com as legislações nacional e estadual $^{7,11}$ que exigem esse documento, com a finalidade de padronização dos procedimentos realizados no processamento das refeições, a fim de garantir a segurança dos alimentos a serem distribuídos aos escolares.

A ausência de procedimentos padronizados pode ser demonstrada pela higienização inadequada de frutas e hortaliças, observada em 83\% das escolas. Como resultado, esse foi o grupo com maior ocorrência $(42,8 \%)$ de E.coli, mesmo que em baixas contagens. É importante a presença das frutas e hortaliças na alimentação escolar, pois são ricas em vitaminas, minerais e fibras e contribuem para a proteção à saúde e a diminuição do risco de ocorrência de várias doenças ${ }^{1,2}$, porém podem ser veículos de agentes causadores de DTA. Em nível global, foram responsáveis, entre 1990 e 2005, por 13\% dos surtos com fonte alimentar identificada, sendo que as saladas verdes foram uma das mais envolvidas em casos de $\mathrm{DTA}^{23}$.

\section{Conclusão}

Na maioria das escolas estudadas, os alimentos servidos aos escolares estavam dentro de padrões higiênico-sanitários adequados, pois não foram encontradas bactérias do gênero Salmonella e Shigella, apenas cinco apresentavam E. coli acima dos parâmetros da legislação e dois tinham a presença de Staphylococcus coagulase positiva. Entretanto, problemas foram detectados no cumprimento da presença do responsável técnico pela alimentação escolar, o que determinou que uma parcela das escolas estivesse em desacordo com as exigências da legislação. Nas escolas estaduais, onde não havia nutricionista para supervisão e controle das rotinas, os escolares recebiam maior quantidade de alimentos de baixo valor nutricional do que nas escolas municipais. Além disso, os alimentos oferecidos nessas escolas apresentavam, com maior frequência, a presença das bactérias pesquisadas, inclusive aqueles alimentos do grupo considerado de menor risco como fonte veiculadora de patógenos. Esse resultado demonstra a necessidade da implantação das BP no ambiente escolar como fator indispensável para que os alunos recebam alimentos seguros. 


\section{Colaboradores}

Os autores ABA Oliveira, R Capalonga, EC Tondo e MRI Cardoso participaram desde a fase de planejamento passando pela execução da pesquisa, análise e interpretação dos resultados encontrados, redação do documento e aprovação da versão final para submissão para publicação. A autora JT
Silveira participou da fase de planejamento, execução da pesquisa e aprovação da versão final.

\section{Agradecimentos}

Ao Fundo Nacional de Desenvolvimento da Educação (FNDE) pelo financiamento do projeto.

\section{Referências}

1. Brasil. Ministério da Saúde (MS). Guia alimentar para a população brasileira: promovendo a alimentação saudável. 1a Edição. Brasília: MS; 2005.

2. United States Departament of Agriculture. Why is it important to eat fruit? Washington: USDA; 2011. [acessado 2011 jun 4]. Disponível em: http://www choosemyplate.gov/foodgroups/fruits_why.html.

3. Fundo Nacional de Desenvolvimento da Educação. Alimentação Escolar. Brasília: Ministério da Educação/FNDE; 2010. [acessado 2010 jul 11]. Disponível em: http://www.fnde.gov.br/index.php/programasalimentacao-escolar

4. Centro de Vigilância Epidemiológica. Doenças Transmitidas por Alimentos, Estado de São Paulo. 1999-2008. São Paulo: CVE; 2008. [acessado 2011 mar 10]. Disponível em: http://www.cve.saude.sp.gov.br/htm/hidrica/hidri_vdtaa.htm

5. Santos LMPS, Santos SMC, Santana LAA, Henrique FCS, Mazza RPD, Santos LAS, Santos LS. Avaliação de políticas públicas de segurança e combate à fome no período 1995-2002. Cad Saude Publica 2007; 23(9): 2681-2693.

6. Brasil. Portaria Interministerial no 1.010 de 08 de maio de 2006. Institui as diretrizes para a promoção da alimentação saudável nas escolas de educação infantil, fundamental e nível médio das redes públicas e privadas, em âmbito nacional. Diário Oficial da União 2006; 08 maio.

7. Rio Grande do Sul. Portaria ${ }^{\circ} 78$ de 14 de setembro 2009. Aprova a Lista de Verificação em Boas Práticas para Serviços de Alimentação, aprova Normas de Capacitação em Boas Práticas para Serviços de Alimentação e dá outras providências. Diário Oficial da União 2009; 15 set.

8. Silva N, Junqueira VCA, Silveira NFA, Taniwaki $M H$ Santos RFS dos, Gomes RAR. Manual de métodos de análise microbiológica de alimentos. 3a Edição. São Paulo: Varela; 2007.

9. Greig JD, Ravel A. Analysis of foodborne outbreak data reported internationally for source attribution. Int J Food Microbiol 2009; 130(2):77-87.

10. Brasil. Resolução de Diretoria Colegiada no 12 de 02 de janeiro de 2001. Aprova o: Regulamento técnico sobre padrões microbiológicos para alimentos. Diário Oficial da União 2001; 02 jan.

11. Brasil. Resolução de Diretoria Colegiada nº 216 de 15 de setembro de 2004. Dispõe sobre Regulamento Técnico de Boas Práticas para Serviços de Alimentação. Diário Oficial da União 2004; 16 set.

12. Andrade NJ. Higiene na Indústria de alimentos: avaliação e controle da adesão e formação de biofilmes bacterianos. São Paulo: Varela; 2008.
13. Michelin AF, Carmo LS, Carlos IZ. Surto de intoxicação alimentar estafilocócica no município de Birigui, São Paulo. Rev Inst Adolfo Lutz 2006; 65(1):46-49.

14. Michino H, Otsuki K. Risk factors in causing out breaks of food-borne illness originating in schoollunch facilities in Japan. J Vet Med Sci 2000 May; 62(5):557-560.

15. De Buyser ML, Dufour B, Maire M, Lafarge V. Implication of milk and milk products in food-borne diseases in France and in different industrialised countries. Int J Food Microbiol 2001; 67(1-2):1-17.

16. Greig JD, Todd EC, Bartleson CA, Michaels BS Outbreaks where food workers have been implicated in the spread of foodborne disease. Part 1. Description of the problem, methods, and agents involved. J Food Prot 2007; 70(7):1752-1761.

17. Londero PMG, Ribeiro ND, Cerutti T, Maziero SM, Rosa DP, Da Rosa SS. Efeito materno na expressão dos teores de aminoácidos sulfurados em grãos de feijão. Ciência Rural 2009; 39(6):1884-1887.

18. Philippi ST. Nutrição e Técnica Dietética. 2a Edição. Barueri: Manole; 2006.

19. Rooke JA, Flockhart JF, Sparks NH. The potential for increasing the concentrations of micro-nutrients relevant to human nutrition in meat, milk and eggs. Journal of Agricultural Science 2010; 148(5):603-614.

20. Todd EC, Greig JD, Bartleson CA, Michaels BS. Outbreaks where food workers have been implicated in the spread of foodborne disease. Part 3. Factors contributing to outbreaks and description of outbreak categories. J Food Prot 2007; 70(9):2199-2217.

21. Organização Pan-Americana de Saúde (OPAS), Organização Mundial da Saúde (OMS). Codex Alimentarius, Higiene dos Alimentos -Textos Básicos. Brasília: Agência Nacional de Vigilância Sanitária, OPAS; 2006. [acessado 201115 fev]. Disponível em: http://www.anvisa.gov.br/divulga/public/alimentos/ codex_alimentarius.pdf.

22. Munhoz PM, Pinto JPdAN, Biondi GF. Conheci mento sobre boas práticas por parte dos manipuladores. Hig Aliment 2008; 22(166/167):29-31.

23. Tauxe RV, Doyle MP, Kuchenmuller T, Schlundt J, Stein CE. Evolving public health approaches to the global challenge of foodborne infections. Int J Food Microbiol 2010; 139(Supl. 1):S16-28.

Artigo apresentado em 10/10/2012

Aprovado em 18/11/2012

Versão final apresentada em 20/12/2012 